\title{
The Effect of Efferent Stimulation on Basilar Membrane Displacement in the Basal Turn of the Guinea Pig Cochlea
}

\author{
Euan Murugasu' ${ }^{1,2}$ and lan J. Russell1 \\ 1School of Biological Sciences, University of Sussex, Falmer, Brighton BN1 9QG, United Kingdom, and \\ 2Ear, Nose, and Throat Department, Royal Sussex County Hospital, Brighton BN2 5BE, United Kingdom
}

Tone-evoked basilar membrane (BM) displacements were measured with a laser diode interferometer from the basal turn of the guinea pig cochlea. The olivocochlear bundle (OCB) was electrically stimulated for $60-80$ msec periods at rates of $<200$ $\mathrm{sec}^{-1}$ via electrodes placed at the point at which the OCB crosses the floor of the fourth ventricle. For tones close to the best or characteristic frequency (CF), OCB stimulation tended to linearize the highly compressive displacement-level functions and to displace the ste:ep, low-level region toward higher intensities along the intensity axis by $<27 \mathrm{~dB}$ sound pressure levels. This shift resulted in a desensitization of the tip of the BM displacement tuning curve that was associated sometimes with downward shifts in the tuning curve CF of $<500 \mathrm{~Hz}$. OCBinduced suppression of the BM response was not associated with a consistent broadening of the tuning curve or with major changes in the phase of the BM response. At frequencies in the low-frequency tail of the tuning curve, OCB stimulation had no observable effect on the motion of the BM. The effect of OCB stimulation on the $B M$ response was blocked by perfusing the scala tympani with $1 \mu \mathrm{M}$ strychnine. Thus, the effect of OCB stimulation on the frequency tuning of the $B M$ is very similar to the effect of OCB stimulation on the sensitivity and frequency tuning of afferent fibers and inner hair cells. The results indicate that the postsynaptic action of the OCB may cause a change in gain of the voltage-dependent outer hair cell motility without observable changes in the stiffness of the cochlear partition or the position of the BM.

Key words: cochlea; basilar membrane displacement; olivocochlear bundle; efferent; frequency tuning; guinea pig; laser diode interferometer
The site of mechanotransduction in the organ of Corti, the mammalian cochlea, is the narrow, fluid-filled subtectorial space that forms the interface between the tectorial membrane (TM) and the cuticular plate of the organ of Corti. The sensory hair bundles of the inner hair cells (IHC) protrude into this space and are thought to be displaced by the viscous drag of fluid flow caused by shear displacements between the TM and the cuticular plate in response to auditory stimulation (Dallos et al., 1972; Dallos, 1973; Sellick and Russell, 1980). The shear displacement imparted to the IHC stereocilia probably is determined in part by the geometry and mechanical properties of the cochlear partition and TM (Allen, 1980; Zwislocki and Kletsky, 1980) and by mechanical feedback (Kemp, 1978; Kim et al., 1980; Weiss, 1982; Davis, 1983) contributed by the voltage-dependent motility of three or more rows of outer hair cells (OHC) (Brcwnell et al., 1985; Ashmore, 1987; Santos-Sacchi and Dilger, 1988; Dallos et al., 1991), hair bundles of which form a structural link between the organ of Corti and the TM. The feedback is believed to be crucial in determining the frequency selectivity and sensitivity that are characteristic of each position along the length of the basilar membrane (BM) and of each hair cell and auditory nerve fiber in the organ of Corti. The presence of the impressive boutons of the olivocochlear bundle (OCB) that terminate on the basal and basolateral membranes of

Received Aug. 22, 1995; revised Sept. 26, 1995; accepted Sept. 29, 1995.

This work was supported by grants from the Medical Research Council, Hearing Research Trust, and Royal Society. E.M. was supported by a Lee Kuan Yew Scholarship and a Burghard Research Fellowship from the Royal College of Surgeons. We thank James Hartley for designing and constructing the electronic apparatus and Ann Brown and Guy Richardson for their critical reading of early versions of this manuscript.

Correspondence should he addressed to Ian J. Russell at the ahove address. Copyright (c) 1995 Society for Neuroscience $0270-6474 / 95 / 160325-08 \$ 05.00 / 0$
OHC has led to speculation that, through the modification of the electrical and mechanical properties of the $\mathrm{OHC}$ and, consequently, the sound-evoked shear displacements between the TM and the cuticular plate, the OCB controls the gain of the feedback and, hence, the sensitivity and frequency selectivity of the cochlea (for review, see Wiederhold, 1986).

Fibers of the OCB exert a predominantly inhibitory effect on the sound-evoked responses of the cochlea. Electrical stimulation of the medial component of the OCB reduces the amplitude of the click-evoked compound action potential (CAP) in the auditory nerve (Galambos, 1956), enhances the cochlear microphonic (CM) (Fex, 1959), and alters the level of acoustic distortion measured at the external auditory meatus (Mountain, 1980). The action of the $\mathrm{OCB}$ on the $\mathrm{OHC}$ is frequency-dependent in that the suppression of both IHC receptor potentials (Brown and Nuttall 1984) and afferent nerve fiber activity (Wiederhold and Kiang, 1970 ) is greatest at the pcak (charactcristic frequency) of the tuning curve (CF).

In this study, we measured the effects of OCB activation on tone-evoked displacements of the BM in the basal, high-frequency turn of the guinea pig cochlea and postulate how the OCB exerts its influence on the sound-evoked responses of the cochlea.

An abstract based on some of the findings reported in this paper has been published previously (Murugasu and Russell, 1994).

\section{MATERIALS AND METHODS}

Animal preparation and electrophysiological recording and stimulation. Young pigmented guinea pigs weighing 180-300 gm from the laboratorymaintained colony were used in this study. The animals were anesthetized with sodium pentobarbitone $(30 \mathrm{mg} / \mathrm{ml})$, phenoperidine $(1 \mathrm{mg} / \mathrm{ml})$, and droperidol (4 mg/ml) (Evans, 1979), and a tracheal cannula was inserted. 
Operidine was administered every $40 \mathrm{~min}$, and the body temperature of the guinea pig was kept at $38^{\circ} \mathrm{C}$ with a heating blanket. The heart rate was monitored via a pair of skin electrodes placed on both sides of the thorax. The right cochlea was exposed through a lateral opening in the temporal bone and was back-illuminated by a fiberoptic light guide inserted through a hole made in the basal wall of the bulla. The BM was exposed through a small fenestra $\sim 1 \mathrm{~mm} \times 0.5 \mathrm{~mm}$ made in the bony wall of the basal turn of the cochlea.

The CAP of the cochlear nerve and the CM were recorded with an electrode placed on the round window. The $\mathrm{Ag}-\mathrm{AgCl}$ reference electrode was inserted in the neck muscles. A fine cannula $(<100 \mu \mathrm{m}$ diameter) was inserted through a small incision in the round window, and HEPES-buffered HBSS ( $\mathrm{pH} 7.4,320 \mathrm{mOsm} / \mathrm{l}$ ) or $1 \mu \mathrm{M}$ solutions of strychnine sulfate in HBSS were perfused at room temperature (22$24^{\circ} \mathrm{C}$ ) through the basal turn of the cochlea at a rate of $2.5 \mu \mathrm{l} / \mathrm{min}$ with a syringe pump. As in Puel et al. (1990) and Fitzgerald et al. (1993), no attempt was made to warm the solution to body temperature because perfusion with artificial perilymph did not cause perceptible changes in either the CAP audiogram or the BM displacement responses to tones. The solution flowed out through the fenestra in the basal turn, where it was collected by a dental point that acted as a fine, absorbent wick. 'I'he wick was positioned so that fluid did not escape into the middle ear, and the shape of the meniscus of the perilymph in the fenestra was kept constant to provide a view of the BM. Thus, only regions basal to the $10 \mathrm{kHz}$ region of the cochlea were perfused fully with HBSS or strychnine solution. In this series of experiments, the criterion for a sensitive preparation was one in which the change in the pure-tone CAP threshold audiogram over the range of $1-25 \mathrm{kHz}$ after exposure of the BM was $<10 \mathrm{~dB}$ sound pressure levels (SPL).

The OCB was stimulated at the point at which it crosses the floor of the fourth ventricle, near the genu of the facial nerve. In 300-400 gm guinea pigs, this is $\sim 3.5-4 \mathrm{~mm}$ rostral to the obex of the medulla. The COCB was stimulated by a simple technique developed in this laboratory in which the muscles and connective tissue overlying the foramen magnum were removed and a small incision was made in the dura covering the foramen; through this incision a pair of flexible, Tefloncoated wire electrodes were advanced rostrally along the floor of the fourth ventricle until the tips were near the point of crossing of the OCB. The electrodes were $200 \mu \mathrm{m}$ in diameter, the tips were separated by $500 \mu \mathrm{m}$, and the insulation was removed to expose $500 \mu \mathrm{m}$ of the tip. The position of the electrodes was adjusted so that a train of 16 pulses $(0.2 \mathrm{msec}$ at $200 / \mathrm{sec}$ with amplitudes of $1-2 \mathrm{~V})$ caused only the tips of the pinna to move. If the whiskers moved, the electrode tips were too far rostral; if the neck muscles contracted, the tips were too far caudal. The stimulus amplitude required to excite the OCB usually was lower than that required to cause muscle contraction and usually did not exceed $1.5 \mathrm{~V}$. Because the impedance of the electrodes measured in situ was $\sim 0.5 \mathrm{M} \Omega$, the current necessary to excite the OCB was only $\sim 3$ $\mathrm{mA}$. After the successful placement of the OCB-stimulating electrodes, the animals were paralyzed with Flaxedil (gallamine triethiodide) ( 0.4 $\mathrm{mg} / \mathrm{kg}$ ) and artificially respired with $95 \% \mathrm{O}_{2} / 5 \% \mathrm{CO}_{2}$. The dose of Flaxedil that was administered (Brown and Nuttall, 1984; Reiter and Lieberman, 1995) was sufficient to abolish visible twitch responses and any that might be detected by the interferometer when directed at the bony wall of the cochlea, even at shock levels 10 -fold greater than those required to excite the OCB.

Measurement of BM displacement. Displacements of the BM were measured by the self-mixing effect of a laser diode. The technique is similar to that using gas lasers (O'Neil and Beardon, 1993), but the interferometer is more compact and easier to implement for in vivo measurements. The self-mixing in a laser diode depends on reflecting back a small proportion of the light emitted by the laser into the laser cavity (Koelink et al., 1992). Interference between light within the cavity and light reflected back into the cavity from the target modulates the intensity of the laser. As the target is displaced along the beam axis, the intensity of the laser varies sinusoidally with a period corresponding to a displacement of $\gamma / 2$, where $\gamma$ is the wavelength of the laser light, $670 \mathrm{~nm}$. For the case of a target oscillating by an amount $r$ around a fixed position $P_{\mathrm{o}}$,

$$
P(t)=P_{\mathrm{o}}+\mathrm{r} \sin (w t),
$$

where $P(t)$ is the target position. Providing that the interferometer is operating around the quadrature point, i.e., the a position at which $P_{\mathrm{o}}$ is an integer function of $\gamma / 2$, the method underestimates $r$ by $<3 \%$ for changes in $r$ of less than $\pm 45 \mathrm{~nm}$ around the quadrature point. The displacement-dependent effect was measured in the signal of the photodiode, which is located behind the laser crystal in the laser diode housing. The bandwidth of the displacement-dependent signal was 200 $\mathrm{kHz}$. Calibration of the signal was achieved by displacing the interferometer a known amount by a piezoelectric driver that moved 12.5 $\mathrm{nm} / \mathrm{V}$. The piezoelectric driver also was fed by an amplified signal from the photodiode that was low-pass-filtered with a corner frequency of $100 \mathrm{~Hz}$, and a $D C$ reference voltage was used to set the quadrature point of the interferometer. This system provided a negative feedback system that enabled the interferometer to track gross movements of the preparation such as those caused by respiratory movements and heartbeat while preserving sensitivity for the high-frequency, tone-cvoked displacements of the BM. Although the experiments were performed on a vibration isolation table (Newport, Irvine, CA), the system could not cope with gross relative movements between the diode and the BM of $>10 \mu \mathrm{m}$. If strong extraneous movements caused the operating point of the interferometer to move away from the quadrature point, there was a pronounced reduction in sensitivity and sometimes a reversal in phase of the apparent motion of the BM. When this happened, in most instances, the measurements were repeated; in other cases, it was possible to correct for the change in gain and phase reversal after the event. The high-pass characteristics of the displacement-measuring system prevented the recording of tonic displacements of the BM that were represented, together with the larger, gross displacements of the preparation, in the feedback signal to the piezoelectric transducer. However, it was possible to measure tonic displacements either by disconnecting the feedback or by monitoring the feedback, providing the relative movements between the interferometer and the preparation were below $\sim 10 \mathrm{~nm}$.

The beam from the laser diode was focused to form a $10-\mu \mathrm{m}$ diameter spot in the middle of the basal turn of the BM. Only light from the plane of focus was reflected back into the laser cavity. The most reflective structures in this region of the BM are the bases of the outer pillar cells and Deiters cells, and it is likely that the measurements of BM displacement reported here are based on reflections from these structures. In these experiments, it was relatively easy to direct the beam to any position on the BM that was visible through the opening in the wall of the basal turn of the cochlea and to compare vibrations of the BM with those of a fixed structure, such as the spiral lamina, that did not produce tuned displacements to tones presented at the tympanic membrane. The frequency range of the BM that was exposed by the opening was $14-19 \mathrm{kHz}$, but most measurements reported here were made near $15 \mathrm{kHz}$.

Acoustic stimulation and measurement. Sound was delivered to the tympanic membrane by a closed acoustic system comprising two Bruel and Kjaer 4133 microphones with $0.625 \mathrm{~cm}$ couplers for delivering tones and a Bruel and Kjaer 3134 probe microphone with a $0.625 \mathrm{~cm}$ coupler for monitoring the sound pressure at the tympanum. Pure-tone stimuli were generated by two Hewlett Packard 325 synthesizers and fed into two computer-controlled gates and into two General Purpose Interface Buscontrolled attenuators (designed and constructed by James Hartley, University of Sussex, Brighton, UK). The sound system was calibrated in situ for frequencies between 1 and $30 \mathrm{kHz}$ such that known sound pressure levels expressed in $\mathrm{dB}\left(\mathrm{dB}\right.$ re $\left.2 \times 10^{-5} \mathrm{~Pa}\right)$ were used in the experiments. The sound system was calibrated before and during the experiment following major procedures including the opening of the middle ear, fenestration of the basal turn of the cochlea, insertion of the OCB electrode and perfusion of the basal turn of the cochlea. Continuous tones and tone bursts are presented at known sound pressure levels, also expressed in this paper in dB SPL (dB, $\left.2 \times 10^{-5} \mathrm{~Pa}\right)$.

Acoustic stimulation and acquisition was controlled by a $\mathrm{PC}$ using ASYST (Keithley) software.

Signal analysis. Voltage signals from the interferometer were amplified and directed to a two-channel lock-in amplifier set in quadrature (EG\&G model 5210, Princeton, NJ). The time constant of the lock-in amplifier was $10 \mathrm{msec}$, and the reference signal was the driving voltage to the high-frequency sound delivery system. Signals from the in-phase and quadrature channels of the lock-in amplifiers were sampled at $0.1-0.5$ msec intervals, and the magnitude of the phasic response of the voltage signal from the interferometer was computed either on-line or from data stored on disk by the PC.

Experimental protocol. The CAP audiogram was measured at critical times throughout the experiment to provide information about any frequency-dependent changes in sensitivity after fenestration of the cochlea or placement of the OCB-stimulating electrodes and during stimulation 

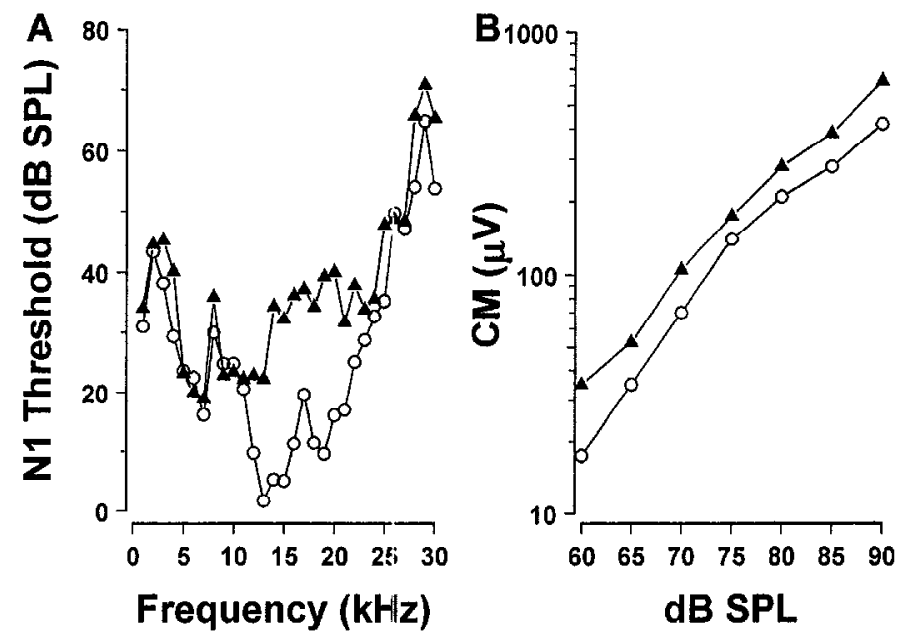

Figure 1. A, CAP audiogram. (O) Audiogram after fenestration of the cochlea to expose the $14-20 \mathrm{kHz}$ region of the BM. (A) Audiogram in which each test tone was preceded by a $60 \mathrm{msec}$ burst of stimulation of the $\mathrm{OCB}$ at $150 \mathrm{sec}^{-1} . B, \mathrm{CM}$ recorded from the round window in response to $1 \mathrm{kHz}$ tones as a function of the level of the tone. (O) Tone alone. (A) CM in which each test tone was preceded by a $60 \mathrm{msec}$ burst of stimulation of the OCB at $150 \mathrm{sec}^{-1}$.

of the OCB. Figure $1 A$ shows the effect of stimulating the OCB on the CAP audiogram in a single preparation. It can be seen that the effect of OCB stimulation is not uniforn across frequencies and is greatest in this preparation for frequencies between 13 and $20 \mathrm{kHz}$. The frequency of maximum suppression of the CAP varied between preparations from $\sim 9$ to $13 \mathrm{kHz}$. Figure $1 B$ shows an example of the augmentation of the $\mathrm{CM}$ recorded at the round window in response to $1 \mathrm{kHz}$ tones after $\mathrm{OCB}$ stimulation, which was recorded at the beginning of each experiment. The augmentation of the CM is an indication that the CAP suppression is attributable to the postsynaptic action of the OCB on the OHC rather than to attenuation of the acoustic signal reaching the cochlca through contraction of the middle ear muscles (Desmedt et al., 1971).

\section{RESULTS}

\section{Level-dependent OCB suppression of BM displacement at CF}

The level- and frequency-dependent action of OCB stimulation on $\mathrm{BM}$ displacement was measured from locations with $\mathrm{CF}$ values between 14.5 and $18 \mathrm{kHz}$ in the basal turn of the cochlea. The effect of OCB stimulation on the displacement of the BM as a function of level (displacement-level function) was measured at the CF of the measuring site (Fig. 2) and at frequencies above and below the CF (Fig. 3). At the CF of the measurement point on the $\mathrm{BM}$, the intensity functions were both sensitive and compressive compared with similar functions obtained at other frequencies. The effect of the OCB stimulation was to reduce the dynamic range of the compressive phase reversibly by $18.3 \pm 4.6 \mathrm{~dB}$ (mean $\pm \mathrm{SD}$ ) (27.6 dB maximum, $14 \mathrm{~dB}$ minimum, $n=7)$ and, hence, to displace the steep, low-level portion of the intensity function toward higher intensities along the intensity axis. OCB stimulation had no apparent effect on BM displacements in response to tones at frequencies more than one-half an octave below or one-third of an octave above the CF; in addition, OCB stimulation did not cause an observable tonic displacement of the BM (data not shown).

\section{Frequency tuning curves during $\mathrm{OCB}$ stimulation}

The frequency dependence of OCB stimulation on BM displacement can be seen in Figures 4,7 , and 8 in which isoresponse frequency functions for six preparations (I-VI) are plotted before
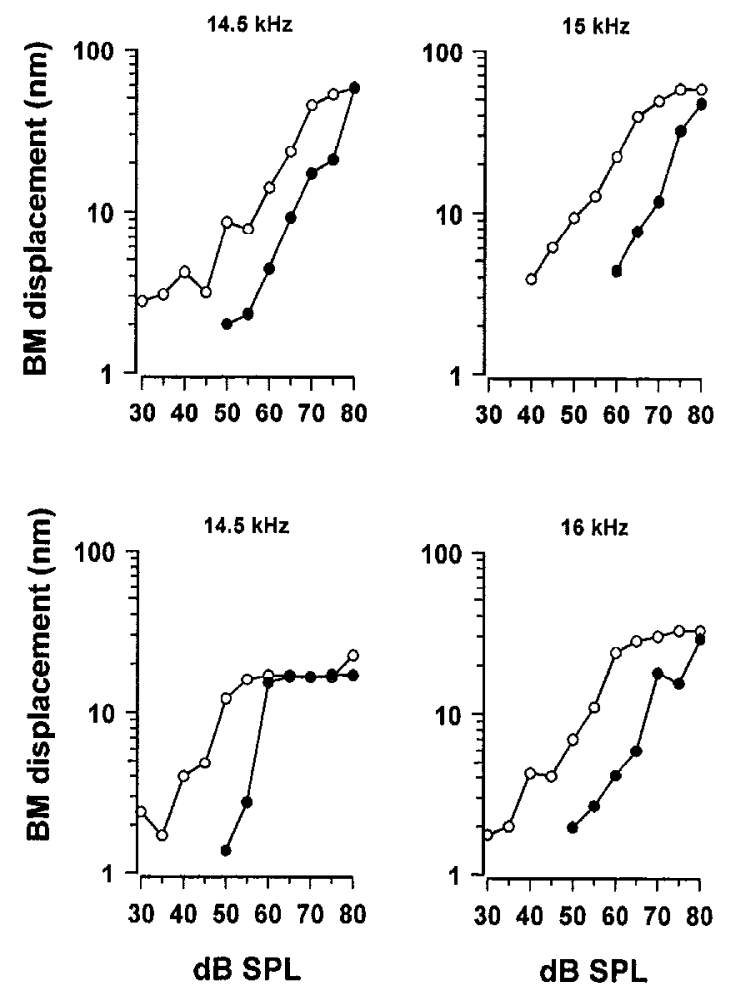

Figure 2. BM displacement as a function of tone level in response to tone alone $(O)$ and accompanied by OCB stimulation ( $)$ from four preparations for frequencies at or near $\mathrm{CF}$.

and during OCB stimulation. The $2 \mathrm{~nm}$ isoresponse tuning curves were derived from intensity functions similar to those shown in Figures 2 and 3 and are based on the SPL required at each frequency to cause a $2 \mathrm{~nm}$ displacement of the BM. The $2 \mathrm{~nm}$ criterion was chosen because it was just within the dynamic range of the displacement-level functions and above the $1-1.5 \mathrm{~nm}$ noise floor of the recording system for single measurements. In each case, there was a significant elevation of the tip of the tuning curve $(18.3 \pm 4.6 \mathrm{~dB}, n=7)$ but no change in the sensitivity of the low-frequency tail. In three preparations there was no change in the CF after OCB stimulation, and in the other three preparations the CF moved $500 \mathrm{~Hz}$ to lower frequencies. There was no significant change in $Q_{10 \mathrm{~dB}}$ (CF divided by the bandwidth, $10 \mathrm{~dB}$ from the tip) after OCB stimulation in one preparation, a slight reduction in the $Q_{10 \mathrm{~dB}}$ in four preparations, and a significant increase in one preparation (VI, see Fig. 8) (see Table 1). There was no correlation between changes in the $\mathrm{CF}$ and $Q_{10 \mathrm{~dB}}$.

\section{OCB suppression of BM displacement is reversibly blocked by strychnine}

Strychnine has been shown to block the inhibitory action of the OCB in the cochlca without altering cochlear thresholds (for review, see Klinke and Galley, 1974; Eybalin, 1993). The BM displacement intensity functions measured at successive times in a single preparation, shown in Figure 5, illustrate the effects of electrical stimulation of the OCB on BM displacement to tones at or close to the CF when the scala tympani first is perfused with artificial perilymph, then during perfusion with $1 \mu \mathrm{M}$ strychnine in artificial perilymph and, finally, after wash-out with artificial perilymph. It can be seen that perfusion with the strychnine solution caused a reversible block of the OCB-induced suppression of the $\mathrm{BM}$ response to tones near the CF. 


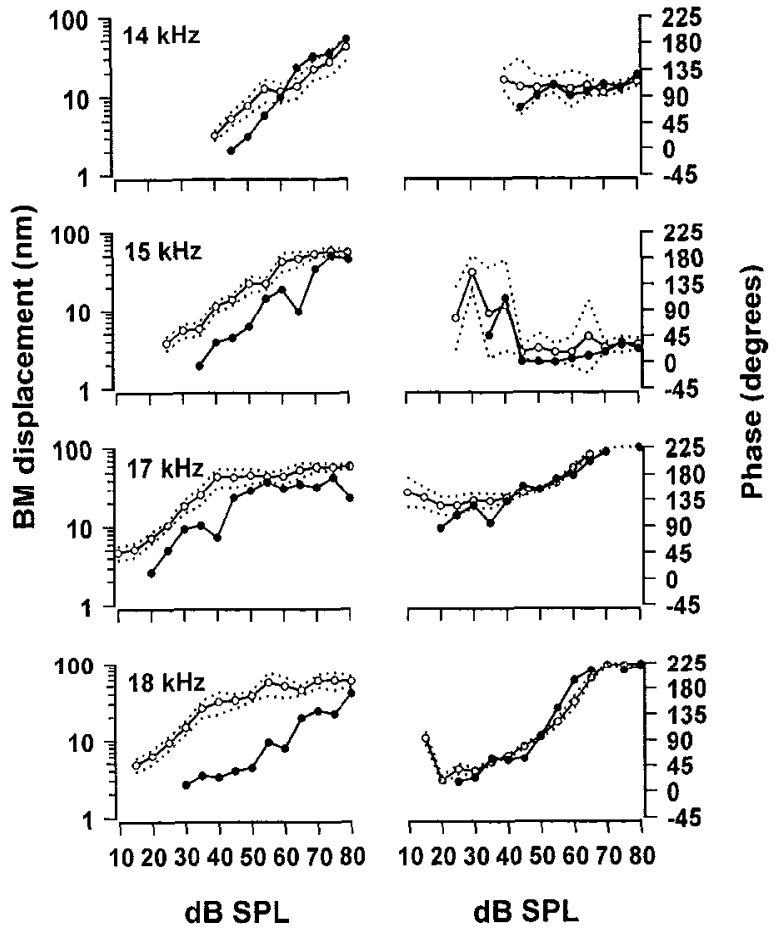

Figure 3. Displacement (left) and phase (right) of the BM as functions of level for a single preparation at different tone frequencies around the $\mathrm{CF}$ $(17.5 \mathrm{kHz})$. (O) Tone alone; $(\bullet)$ tone accompanied by OCB stimulation. (....) \pm SD of five successive measurements for the control only.

\section{The effect of OCB stimulation on the phase of BM displacement}

The phase of the BM displacement as a function of frequency compared with the microphone-driving voltage was measured to see how the phase was influenced by OCB stimulation. Phase was measured as a function of frequency at a constant level (Fig. 6) and as a function of level at constant frequency with and without OCB stimulation (Figs. 2, 3). From such measurements, it was possible to measure the phase of the $\mathrm{BM}$ as a function of frequency at constant displacement. Examples of the phase of $2 \mathrm{~nm}$ displacements of the BM as a function of the frequency of the tone are shown in Figure $7 A$ and, for displacements of 2 and 10 $\mathrm{nm}$, in Figure $8 A$. In both figures, COCB stimulation does not appear to change the phase of the tone-evoked BM displacements at either of the isoresponse criteria. In Figure 8, which is derived from the data shown in Figure 3, there are no clear phase differences between the 2 and $10 \mathrm{~nm}$ responses. However, the bandwidth of the tuning curve in this preparation became narrower at $10 \mathrm{~nm}$ criterion $\left(Q_{10 \mathrm{~dB}}=6.7\right)$ compared with the $2 \mathrm{~nm}$ criterion $\left(Q_{10 \mathrm{~dB}}=5.5\right)$. With OCB stimulation, the bandwidths at $2 \mathrm{~nm}\left(Q_{10 \mathrm{~dB}}=10.1\right)$ and $10 \mathrm{~nm}\left(Q_{10 \mathrm{~dB}}=13.1\right)$ were reduced even further.

\section{DISCUSSION}

Data presented in this paper show that electrical stimulation of the OCB changes tone-evoked displacements of the cochlear partition. These changes are reflected in a reduction in the sensitivity of $\mathrm{BM}$ displacement to tones near the $\mathrm{CF}$ by up to $27 \mathrm{~dB}$ SPL. A similar OCB-induced reduction in BM velocity in the basal turn of the guinea pig cochlea was reported in an abstract by Dolan and Nuttall (1994). As in other desensitizing manipulations of the cochlea, such as two-tone suppression (Rhode, 1977;
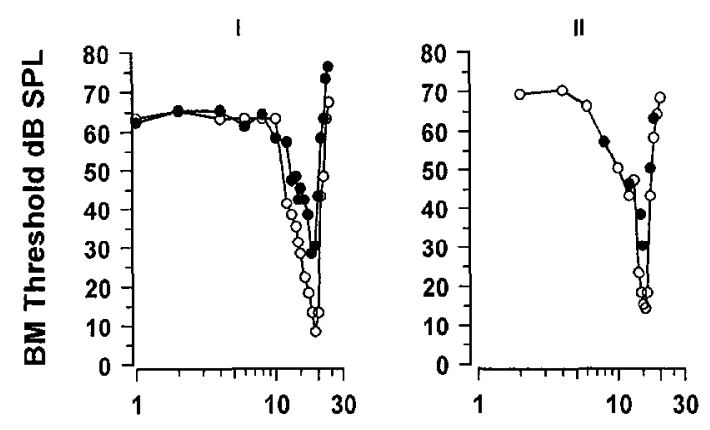

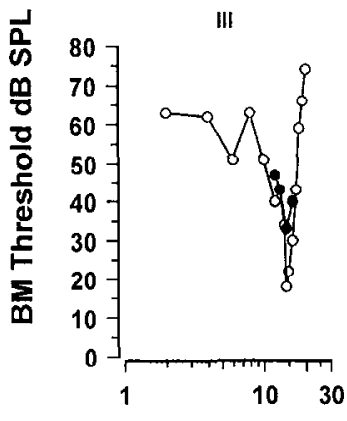

Frequency $(\mathrm{kHz})$

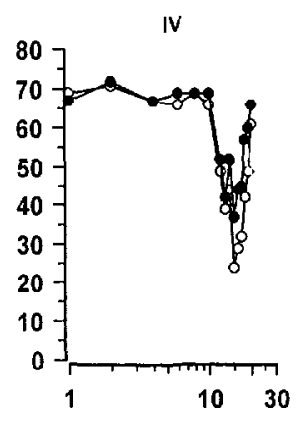

Frequency $(\mathbf{k H z})$
Figure 4. Isoresponse tuning curves for BM displacements of $2 \mathrm{~nm}$ for the tone presented alone $(O)$ and during OCB stimulation $(O)$ from four preparations. Each preparation is identified by a roman numeral for comparison with the data in Table 1.

Robles et al., 1991), noxious agents (Ruggero and Rich, 1991; Murugasu and Russell, 1995), and intense tones (Patuzzi et al., 1984; Cooper and Rhode, 1992), stimulation of the OCB tended to linearize the initially highly compressive displacement-level functions and shift them along the level axis toward higher SPL. However, there was no equivalent shift in the phase-level functions (Fig. 3) or in the isoresponse phase-frequency relationships (Figs. 7,8 ). Thus, the cffects of OCB stimulation on the magnitude and phase of BM displacement were similar to the effects of OCB stimulation on neural rate-level functions reported by Wiederhold (1970) and Teas et al. (1972) and neural phase (Gifford and Guinan, 1983) for low-level tones.

OCB-induced suppression of the BM response was not associated with a consistent broadening of the tuning curve and, in preparation VI, it was associated with a marked decrease in the bandwidth of the tuning curve (increase in $Q_{10 \mathrm{~dB}}$ ). The bandwidths of isoresponse tuning curves based on suprathreshold criteria can be narrower than those of threshold tuning curves

Table 1. CF and bandwidth measures
\begin{tabular}{lllll} 
No. & $\mathrm{CF}(\mathrm{kHz})$ & $\mathrm{CF}_{\text {eff }}(\mathrm{kHz})$ & $Q_{\text {10dB }}$ & $Q_{\text {10dBeff }}$ \\
\hline I & 19 & 18.5 & 6.6 & 6.2 \\
II & 14.5 & 14.5 & 7.0 & 7.0 \\
III & 14.5 & 14.5 & 7.8 & 5.6 \\
IV & 15 & 15 & 5.7 & 5.6 \\
V & 16.5 & 16.0 & 7.6 & 6.8 \\
VI & 17.5 & 17.0 & 5.5 & 10.1
\end{tabular}

The $\mathrm{CF}$, the $\mathrm{CF}$ after stimulation of the $\mathrm{OCB}\left(\mathrm{CF}_{\text {eff }}\right)$, the bandwidth measure $10 \mathrm{~dB}$ from the tip divided by the $C F\left(Q_{10 \mathrm{~dB}}\right)$, and $Q_{10 \mathrm{~dB}}$ after stimulation of the $O C B$ $\left(Q_{\text {10dBent }}\right)$ for six preparations (No.) are shown. 


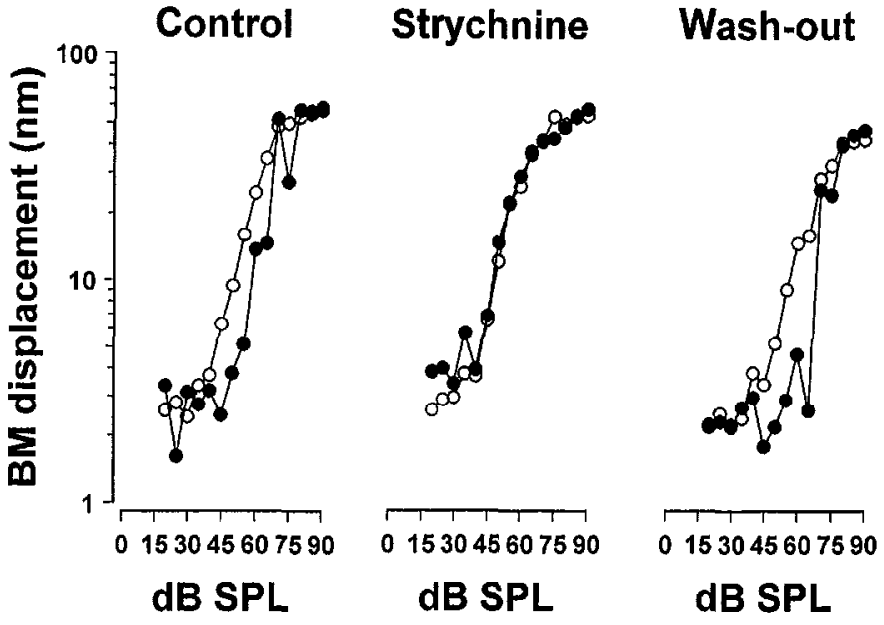

Figure 5. BM displacement as a function of tone level in response to tone alone $(O)$ and accompanied by OCB stimulation $(\Theta)$ from a single preparation $(\mathrm{CF}=17 \mathrm{kHz})$ in response to a $15 \mathrm{kHz}$ tone. Control, During a 10 min perfusion of the scala tympani of the basal turn with artificial perilymph. Strychnine, After a $10 \mathrm{~min}$ perfusion of the scala tympani with $1 \mu \mathrm{M}$ strychnine. Wash-out, After a 15 min perfusion with artificial perilymph.

(Evans, 1972; Russell and Sellick, 1978) for IHC. However, the narrowing of the isoresponse tuning curve in preparation VI after OCB stimulation was far greater than that obtained by increasing the criterion on which the tuning curve is based (from 2 to $10 \mathrm{~nm}$ ) and appeared to be attributable to strong inhibition of the BM displacement to tones at frequencies on the high and low frequency slopes of the tuning curve peak. The slight downward shift of the CF of $\sim 500 \mathrm{~Hz}$, also seen in preparations I and V, was caused by stronger inhibition of BM responses to frequencies at and just above the $\mathrm{CF}$ than to frequencies below it. At frequencies in the low-frequency tail of the tuning curve, OCB stimulation had no observable effect on the motion of the BM. Strychnine, a powerful blocker of the effects of OCB stimulation on the receptor potentials and neural activity of the cochlea, also blocked the effect of OCB
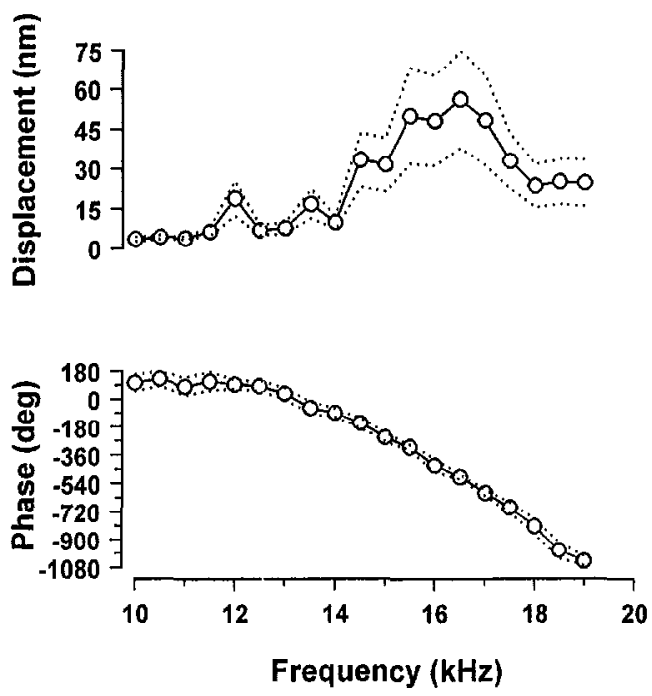

Figure 6. Displacement (top) and phase (bottom) of the BM as functions of tone frequency at constant level $(50 \mathrm{~dB}$ SPL). $(\cdots)$ ISD of five successive measurements. $\mathrm{CF}=:=17 \mathrm{kHz}$.
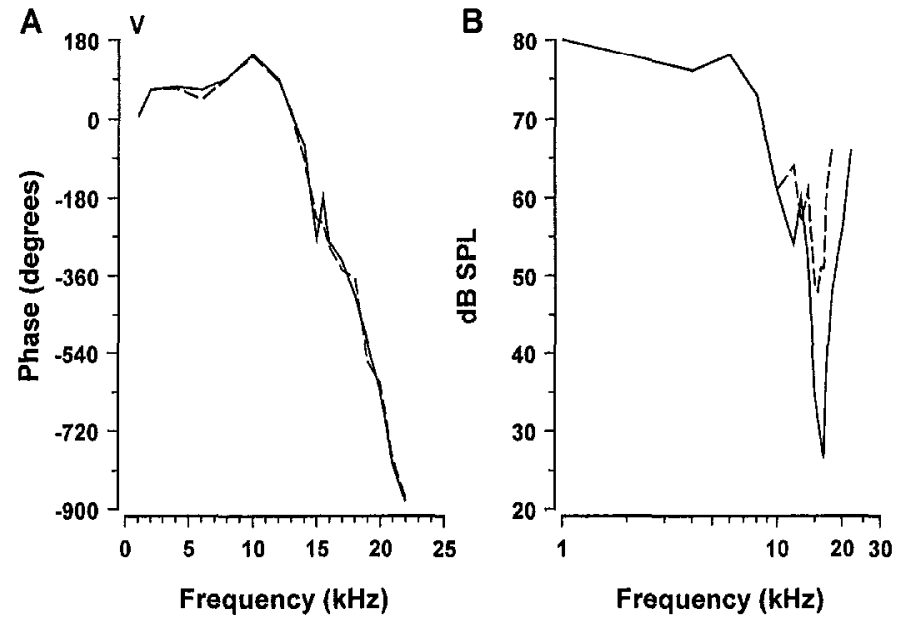

Figure 7. Phase and magnitude of tone-evoked BM displacements of preparation V. $A$, Phase of BM displacement as a function of frequency for $\mathrm{BM}$ displacements of $2 \mathrm{~nm}(-)$ and during $\mathrm{OCB}$ stimulation $(---), B$, BM isoresponse tuning curves for $2 \mathrm{~nm}$ criterion $(-)$ and during $\mathrm{OCB}$ stimulation (....-).

stimulation on tone-evoked displacements of the BM when perfused into the scala tympani in concentrations of $1 \mu \mathrm{M}$. Thus, the effect of OCB stimulation on tone-evoked displacements of the BM is very similar to previous reports of the effect of OCB stimulation on the sensitivity and frequency tuning of afferent fibers (Fex, 1962; Wiederhold, 1970; Wiederhold and Kiang, 1970; Gifford and Guinan, 1983) and inner hair cells (Brown and Nuttall, 1984).

\section{How could OCB stimulation control the mechanical responses of the BM?}

I'here are several ways in which OCB stimulation might influence the responses of the BM. For example, OCB stimulation could causc a decrcase in the stiffncss of the cochlear partition, or it could reduce the $\mathrm{OHC}$ feedback to the cochlear partition by biasing either the transducer conductance or the OHC electro-
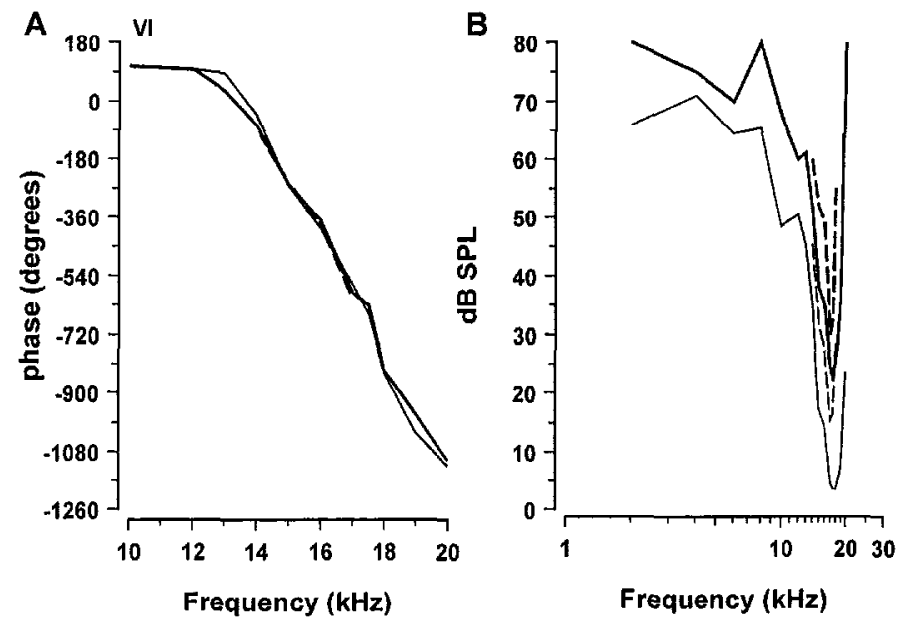

Figure 8. Phase and magnitude of tone-evoked BM displacements of preparation VI. $A$, Phase of BM displacement as a function of frequency for BM of $2 \mathrm{~nm}$ (thin line), during OCB stimulation (dashed line), for 10 $\mathrm{nm}$ displacements (thick line), and during OCB stimulation (thick dashed line). $B, \mathrm{BM}$ isoresponse tuning curves for $2 \mathrm{~nm}$ criterion (thin line), during OCB stimulation (dushed line), for $10 \mathrm{~nm}$ criterion (thick line), and during OCB stimulation (thick dashed line). 
motility away from their most effective operating points (Patuzzi and Rajan, 1990). Also, via changes in the OHC basolateral conductances, one consequence of OCB activation could be effectively to shunt transmembrane or transcellular voltages (Fex, 1962; Flock and Russell, 1973; Wiederhold, 1986) away from the OHC motor, thereby reducing feedback from the OHC motility to the cochlear partition.

\section{Does OCB stimulation cause a change in the stiffness of the cochlear partition?}

The forces exerted by $\mathrm{OHC}$ are related to their turgor pressure and axial stiffness and treatments, including salicylate, which reduce $\mathrm{OHC}$ turgor and thereby decrease the magnitude of the electromotility (Brownell et al., 1989a,b; Shehata et al., 1991; Russell and Schauz, in press). The axial stiffncss of OHC has bcen shown to contribute significantly to the transverse stiffness of the cochlear partition. After perfusion of the scala tympani with salicylate, the sensitivity and frequency selectivity of the BM isoresponse tuning curve were decreased, the CF was shifted to lower frequencies, and the low-frequency tail of the tuning curve was sensitized (Murugasu and Russell, 1995). However, after OCB stimulation, the tip of the tuning curve was not broadened consistently, the CF did not undergo large shifts to lower frequencies, there was no observable increase in the sensitivity of the tuning curve tail, and there was no reduction in the rate of change in the phase of BM displacement near the $\mathrm{CF}$...changes that might have been expected if the transverse stiffness of the cochlear partition were reduced significantly (Allen, 1990). It is unlikely, therefore, that efferent stimulation changes the stiffness of the cochlear partition.

\section{Does OCB stimulation reduce the driving voltage to the cochlear amplifier?}

The sensitivity and frequency selectivity of BM responses to tones are degraded reversibly when the current flow through the transducer conductance and, hence, the driving voltage to the OHC motor are reduced (Ruggero and Rich, 1991). If the postsynaptic action of the OCB is similar to that of efferent fibers in other sense organs of the acousticolateralis system (Flock and Russell, 1973; Ashmore and Russell, 1982; Art et al., 1984), then the flow of receptor current through the transducer conductance is likely to be enhanced by OCB stimulation as a consequence of driving the $\mathrm{OHC}$ membrane potential toward the potassium equilibrium potential $\left(E_{\mathrm{K}}\right)$. The finding that CM is increased during OCB stimulation (Fex, 1959) (see Fig. $1 B$ ) supports this proposal. However, the action of the OCB is inhibitory. To explain this apparent anomaly, it was proposed that the postsynaptic action of the efferent fibers reduced the membrane resistance and, hence, shunted the receptor current (Fex, 1962; Flock and Russell, 1973; Wiederhold, 1986). For lateral line and vestibular hair cells, the combination of reduced membrane resistance and hyperpolarization will reduce both the driving voltage for the control of afferent transmitter release and the probability of opening of the voltage-controlled calcium channels and, consequently, the release of afferent transmitter (for review, see Roberts et al., 1988). Presumably, a similar shunting action by the OCB would reduce the driving voltage to the voltage-dependent motility. However, the magnitude of phasic, transmembrane potential changes is strongly susceptible to changes in membrane resis- tance only for frequencies well below the cut-off frequency of the electrical low-pass filtering of the hair cell. Above this frequency ( $\sim 1 \mathrm{kHz}$ for basal turn OHC; Russell et al., 1986), the electrical impedance of the hair cell is dominated by membrane capacitance, and changes in basolateral membrane resistance have little effect on the magnitude of the $\mathrm{AC}$ component of the receptor potential (Russell and Kössl, 1991). It is unlikely, therefore, that stimulation of the OCB shunts the driving voltage from the $\mathrm{OHC}$ voltage-dependent motility.

\section{Does OCB stimulation alter the operating points of forward and reverse transduction?}

Forward transduction (the displacement-dependent gating of the hair cell transducer channels) and reverse transduction (the voltagedependent mechanical feedback from the $\mathrm{OHC}$ ) are nonlinear processes (for review, see Hudspeth, 1989; Dallos, 1992). OHC in the basal turn of the guinea pig cochlea operate around a point of their transducer function near the maximum slope of the transducer function, where the DC component is minimal (Russell et al., 1986; Russell and Kössl, 1992a). Displacements of the BM either toward or away from the scala tympani reduce the sensitivity and frequency selectivity of the cochlea presumably by displacing the $\mathrm{OHC}$ transducer conductance away from its optimal operating position (Patuzzi and Sellick, 1984; Russell and Kössl, 1992b). Stimulation of the OCB did not cause measurable tonic displacements of the BM. In fact, Patuzzi and Rajan (1990) have estimated that the lengthening of the OHC caused by OCB-induced hyperpolarization should move the $\mathrm{BM}$ by between 0.7 and $1.3 \mathrm{~nm}$ toward the scala vestibuli during OCB stimulation, which is near the noise floor for single measurements reported here. They concluded that such displacements are unlikely to cause a significant reduction in the sensitivity of the $\mathrm{OHC}$ transducer, a doubt that is substantiated by the observed increase in $\mathrm{CM}$ during $\mathrm{OCB}$ stimulation. Therefore, it is unlikely that $\mathrm{OCB}$ stimulation causes a significant shift in the operating point for forward transduction.

The relationship between $\mathrm{OHC}$ membrane potential and $\mathrm{OHC}$ motility is voltage-sensitive (Santos-Sacchi and Dilger, 1988; Santos-Sacchi, 1989). Santos-Sacchi et al. (1994) found that the point of maximal gain can vary from $0 \mathrm{mV}$, at which the $\mathrm{OHC}$ would be completely depolarized, to near $-70 \mathrm{mV}$, which is similar to the resting potential of OHC measured in situ (Dallos et al., 1982; Russell and Sellick, 1983). The operating point of the voltage-dependent motility is displaced toward the insensitive region of operation when the OHC membrane potential is made more negative (Ashmore, 1987; Santos-Sacchi and Dilger, 1988) and when the OHC turgor is increased (Kakehata and SantosSacchi, 1995), as it can be during prolonged hyperpolarization (Shehata et al., 1991). Thus, even quite small levels of OCBinduced hyperpolarization, while increasing the driving voltage for the transducer current, could displace the operating point of reverse transduction further away from the optimum operating position, thus reducing the gain of the cochlear amplifier and feedback to the cochlear partition.

\section{REFERENCES}

Allen JR (1980) Cochlear micromechanics: a physical model of transduction. J Acoust Soc Am 68:1660-1670.

Allen JB (1990) Modelling the noise damaged cochlea. In: The mechanics and biophysics of hearing (Dallos P, Geisler CD, Mathews JW, Ruggero MA, Steele CR, eds), pp 324-332. New York: Springer. 
Art JJ, Fettiplace R, Fuchs PA (1984) Synaptic hyperpolarization and inhibition of turtle cochlear hair cells. J Physiol (Lond) 356:525-550.

Ashmore JF (1987) A fast motile response in guinea pig outer hair cells: the cellular basis of the cochlear amplifier. J Physiol (Lond) 388:323-347.

Ashmore JF, Russell IJ (1982) Effect of efferent nerve stimulation on hair cells of the frog sacculus. J Physiol (Lond) 329:25P-26P.

Brown MC, Nuttall AL (1984) Efferent control of cochlear inner hair cell responses in the guinea pig. J Physiol (Lond) 354:625-646.

Brownell WF, Bader CR, Bertrand D, Ribaupirre Y (1985) Evoked mechanical responses of isolated cochlear outer hair cells. Science 227:194-196.

Browncll WE, Imredy JB, Shehata W (1989a) Stimulated volume changes in mammalian outer hair cells. Proc Annu Int Cong IEEE Eng Med Bil Soc 11:1344-1345.

Brownell WE, Shehata W, Imredy JB (1989b) Slow electrically and chemically evoked volume changes in guinea pig outer hair cells. In: Biomechanics of active movement and deformation of cells (Akas N, ed), pp 493-498. New York: Springer.

Cooper NP, Rhode WS (1992) Basilar membrane mechanics in the hook region of the cat and guinea-pig cochleae: sharp tuning and nonlinearity in the absence of baseline position shifts. Hear Res 63:163-190.

Dallos P (1973) Cochlear potentials and cochlear mechanics. In: Basic mechanisms in hearing (Müller $\AA$ R, ed), pp 335-372. New York: Academic.

Dallos P (1992) The active cochlea. J Neurosci 12:4575-4585.

Dallos P, Billone MC, Durrant JD, Wang CY, Raynor S (1972) Cochlear inner and outer hair cells: functional differences. Science 177:356-358.

Dallos P, Evans BN, Hallworth R (1991) On the nature of the motor element in cochlear outer hair cells. Nature 350:155-157.

Dallos P, Santos-Sacchi J, Flock \& (1982) Intraccllular recordings from outer hair cells. Science 218:582-584.

Davis H (1983) An active processing in cochlear mechanics. Hear Res 9:79-90.

Desmedt JE, LaGrutta V, LaGrutta G (1971) Contrasting effects of centrifugal olivo-cochlear inhibition and of middle ear muscle contraction on the response characteristics of the cat's auditory nerve. Brain Res 30:375-384.

Dolan DF, Nuttall AL (1994) Basilar membrane movement evoked by sound is altered by electrical stimulation of the crossed olivocochlear bundle. Assoc Res Otolaryngol Abstr 17:356.

Evans EF (1972) The frequency response and other properties of single fibres in the guinea pig cochlear nerve. J Physiol (Lond) 226:263-287.

Evans EF (1979) Neuroleptanaesthesia for the guinea pig: an ideal anaesthetic procedure for long term physiological studies of the cochlea. Arch Otolaryngol 105:185-186.

Eybalin M (1993) Neurotransmitter and neuromodulators of the mammalian cochlea. Physiol Rev i3:309-373.

Fex J (1959) Augmentation of cochlear microphonic by stimulation of efferent fibres to the cochlea. Acta Otolaryngol 50:540-541.

Fex J (1962) Auditory activity in centrifugal and centripetal cochlear fibres in the cat. Acta Physiol Scand [Suppl] 55:189.

Fitzgerald JJ, Robertson D, Iohnstone BM (1993) Effects of intracochlear perfusion of salicylates on cochlear microphonic and other auditory responses in the guinea pig. Hear Res 67:147-156.

Flock $\AA$, Russell IJ (1973) Efferent fibres: postsynaptic action on hair cells. Nature New Biol 243:89-91.

Galambos R (1956) Suppression of auditory activity by stimulation of efferent fibres of the cochlea. J Neurophysiol 19:424-437.

Gifford ML, Guinan JJ (1983) Effects of crossed-olivocochlear-bundle stimulation on cat auditory nerve fiber responses to tones. J Acoust Soc Am 74:115-123.

Hudspeth AJ (1989) How the ears works work. Nature 341:397-404.

Kakehata S, Santos-Sacchi J (1995) Membrane tension directly shifts voltage dependence of outer hair cell motility and associated gating charge. Biophys J 68:2190-2197.

Kemp DT (1978) Stimulated acoustic emissions from within the human auditory system. I Acoust Soc Am 64:393-406.

Kim DO, Molnar CE, Mathews JW (1980) Cochlear mechanics: nonlinear behaviour in two-tone responses as reflected in cochlear nerve fiber responses in ear-canal sound pressure. J Acoust Soc $\mathrm{Am}$ $67: 1704-1721$
Klinke R, Galley N (1974) Efferent innervation of vestibular and auditory receptors. Physiol Rev 54:316 357.

Koelink MH, Slot M, de Mul FF, Greve J, Graaff R, Dassel ACM, Aardnoudse JG (1992) Laser Doppler velocimeter based on the selfmixing effect in a fiber-coupled semiconductor laser: theory. Applied Optics 18:3401-3408.

Mountain DC (1980) Changes in endolymphatic potential and crossed olivocochlear bundle stimulation alter cochlear mechanics. Science 210:71-72.

Murugasu E, Russell IJ (1994) The influence of efferent stimulation on basilar membrane mechanics in the guinea pig cochlea. Br J Audiol 29:33-34

Murugasu E, Russell IJ (1995) Salicylate ototoxicity: effects on basilar membrane displacement, cochlear microphonics, and neural responses in the basal turn of the guinea pig cochlea. Auditory Neurosci $1: 139-150$

O'Neil MP, Beardon A (1993) The amplitude and phase of basilar membrane motion in the turtle measured with laser-feedback interferometry. In: Biophysics of hair cell sensory systems (Duifhuis $\mathrm{H}$, Horst JW, van Dijk P, van Netten SM, eds), pp 398-405. Singapore: World Scientific.

Patuzzi R, Johnstone BM, Sellick PM (1984) The alteration of the vibration of the basilar membrane produced by loud sound. Hear Res 13:99-100.

Patuzzi R, Rajan R (1990) Does electrical stimulation of the crossedolivo-cochlear bundle produce movement of the organ of Corti? Hear Res 45:15-32.

Patuzzi R, Sellick PM (1984) The modulation of the sensitivity of the mammalian cochlea by low frequency tones. II. Inner hair cell receptor potentials. Hear Res 13:9-18.

Puel J-L, Bobbin RP, Fallon M (1990) Salicylate, mefenamate, meclofenatc and quininc on cochlcar potentials. Otolaryngol Hcad Ncck Surg 102:66-73.

Reiter ER, Liberman CM (1995) Efferent-mediated protection from acoustic overexposure: relation to slow effects of olivocochlear stimulation. J Neurophysiol 73:506-514.

Rhode WS (1977) Some observations of two-tone measurements using the Mössbauer effect. In: Psychophysics and physiology of hearing (Evans EF, Wilson PA, eds), pp 27-38. New York: Academic.

Roberts WM, Howard J, Hudspeth J (1988) Hair cells: transduction, tuning, and transmission in the inner ear. Annu Rev Cell Biol 4:63-92.

Robles L, Ruggero MA, Rich NC (1991) Two tone distortion in the basilar membrane of the cochlea. Nature 349:413-414.

Ruggero MA, Rich NC (1991) Furosemide alters the organ of Corti mechanics: evidence for feedback of outer hair cells on the basilar membrane. J Neurosci 11:1057-1067.

Russell IJ, Cody AR, Richardson GP (1986) The responses of inner and outer hair cells in the basal turn of the guinea pig cochlea and in the mouse cochlea grown in vitro. Hear Res 22:199-216.

Russell IJ, Kössl M (1991) The voltage responses of hair cells in the basal turn of the guinea pig cochlea. J Physiol (Lond) 435:493-511.

Russell IJ, Kössl M (1992a) Sensory transduction and frequency selectivity in the basal turn of the guinea pig cochlea. Philos Trans R Soc Lond B 336:317-324.

Russell IJ, Kössl M (1992b) Modulation of hair cell voltage responses to tones by low-frequency biasing of the basilar membrane in the guinea pig cochlea. J Neurosci 12:1587-1601.

Russell IJ, Schauz C (1995) Salicylate ototoxicity: effects on the stiffness and electromotility of outer hair cells isolated from the guinea pig cochlea. Auditory Neurosei 1:309-319.

Russell IJ, Sellick PM (1978) Intracellular studies of hair cells in the mammalian cochlea. J Physiol (Lond) 284:261-290.

Russell IJ, Sellick PM (1983) Low frequency characteristics of intracellularly recorded receptor potentials in guinea pig cochlear hair cells. J Physiol (Lond) 284:261-290.

Santos-Sacchi J (1989) Asymmetry in voltage-dependent movements of isolated outer hair cells from the organ of Corti. $\mathbf{J}$ Neurosci 9:2954-2962

Santos-Sacchi J, Dilger JP (1988) Whole cell currents and mechanical responses of isolated outer hair cells. Tissue Cell Res 229:467-481.

Santos-Sacchi J, Huang G-J, Kakehata S (1994) Variability of voltage dependency of the outer hair cell motility voltage sensor. $\mathbf{J} \Lambda$ coust Soc Am 95:2841. 
Sellick PM, Russell IJ (1980) The responses of inner hair cells to basilar membrane velocity during low frequency auditory stimulation in the guinea pig cochlea. Hear Res 2:439-445.

Shehata WE, Brownell WE, Dieler R (1991) Effects of salicylate on shape, electromotility and membrane characteristics of isolated outer hair cells from guinea pig cochlea. Acta Otolaryngol 111:707-718.

Teas DC, Konishi T, Nielson DN (1972) Electrophysiological studies on the spatial distribution of the crossed olivocochlear bundle along the guinea pig cochlea. J Acoust Soc Am 51:1256-1264.

Weiss T (1982) Bidirectional transduction in vertebrate hair cells: a mechanism for coupling mechanical and electrical processes. Hear Res $7: 353-360$.
Wiederhold ML (1970) Variations in the effect of electrical stimulation of the crossed olivocochlear bundle on cat single auditory nerve fiber responses to tone bursts. J Acoust Soc Am 48:966-977.

Wiederhold ML (1986) Physiology of the olivocochlear system. In: Neurobiology of hearing (Altschuler RA, Hoffman DW, Bobbin RP, eds), pp 349-371. New York: Raven.

Wiederhold ML, Kiang NYS (1970) Effects of electrical stimulation of the crossed olivocochlear bundle on single auditory nerve fibers in the cat. J Acoust Soc Am 48:950-965.

Zwislocki JJ, Kletsky EJ (1980) Micromechanics in the theory of cochlear mechanics. Hear Res 2:505-512.mixing effect in a fibre-coupled semiconductor laser: theory. Applied Optics 18:3401-3408. 